\title{
Oncocytic adrenal carcinoma with production of testosterone and cortisol: case report.
}

Michal Krcma

Endocrinology, 1st Dept. of Clinic Medicine, Teaching Hospital and Charles University Plzen, Czech Republic

\section{P R E S E N T A T I O N O F C A S E}

This case is about X.Y., 29-yr woman with no concomitant illnesses in her history and with negative family history in sense of adrenal or cancer disease. She was after abortion due to severe congenital anomaly at age 25 , and after normal pregnancy at age 27 years.

She came in our clinic first in February 2012 for secondary hypomenorrhea lasting for 3 months, hirsutism and worsening of acne. Laboratory examination revealed markedly elevated free testosterone $(9.6 \mathrm{nmol} / \mathrm{l})$ and slightly elevated morning cortisol $(687.4 \mathrm{nmol} / \mathrm{l})$ with almost no suppression in low dose dexamethasone suppression test (1mg) and elevated DHEA-S.

Baseline hormonal profile

\begin{tabular}{|l|l|}
\hline morning cortisol & $751 \mathrm{pmol} / \mathrm{I}$ \\
\hline free testosterone & $\mathbf{9 . 6} \mathrm{nmol} / \mathrm{I}$ \\
\hline free androgen index & 40.0 \\
\hline DHEAS & $3.6 \mathrm{nmol} / \mathrm{I}$ \\
\hline SHBG & $24 \mathrm{nmol} / \mathrm{I}$ \\
\hline TSH & $1.33 \mathrm{mIU} / \mathrm{ml}$ \\
\hline ACTH & $<1.0 \mathrm{pmol} / \mathrm{I}$ \\
\hline
\end{tabular}

Due to testosterone level, CT scan was performed. On CT scan was diagnosed multinodular adrenal tumor $70 \times 45 \mathrm{~mm}$ (60 HU) in right adrenal gland, left adrenal was normal. In lower part of right liver lobe was small hypodense locus $21 \mathrm{x}$ $15 \mathrm{~mm}$ suspected to metastasis.
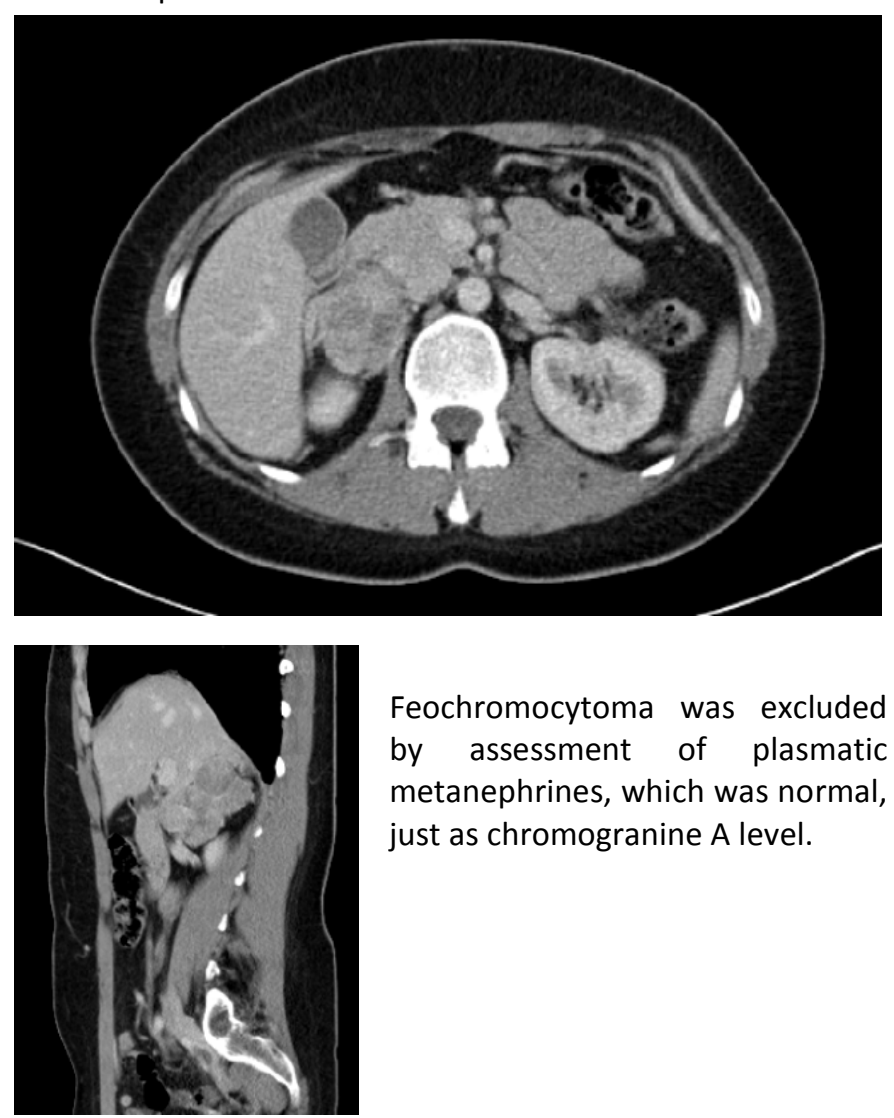

Feochromocytoma was excluded by assessment of plasmatic metanephrines, which was normal, just as chromogranine A level.

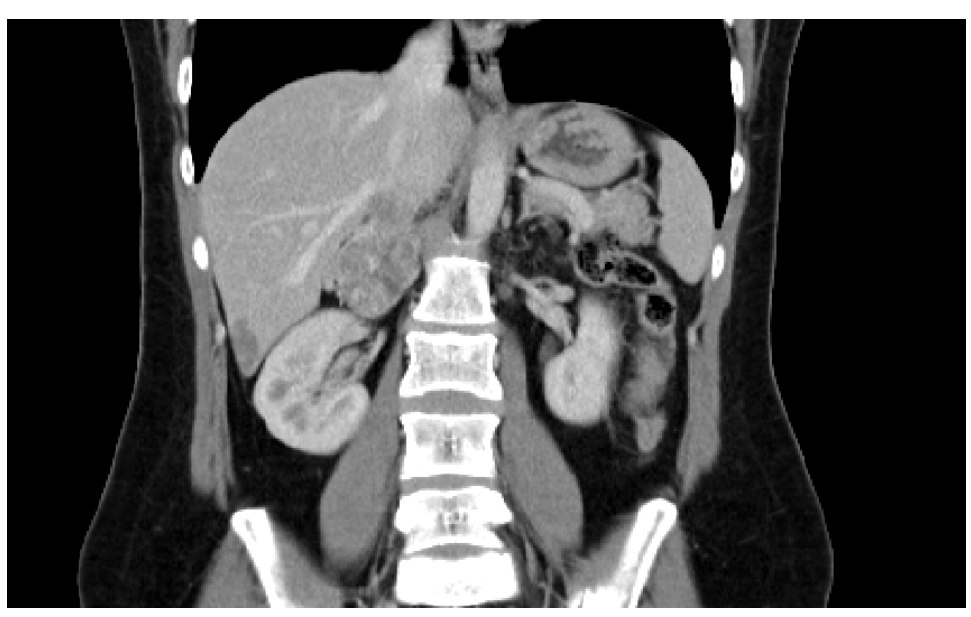

T R E A T M E N T

In April 2012 surgery was performed - open wedge-shaped excision of liver tumor and right adrenalectomy, biopsy of liver was benign - cavernous haemangioma. Biopsy of adrenal gland was described surprisingly in first reading as feochromocytoma. After surgery, menstruation cycle, hirsutism, acne, level of plasma cortisol, free testosterone and cortisol after suppression were normalized.

For clinical discrepancy (negative metanephrines before surgery, cortisol + testosterone production) we initiated second reading of adrenal biopsy and the conclusion was oncocytic variant of adrenal carcinoma (cellular lesion, partially necrotic, with 6 mitoses per visual field, proliferation index $15 \%$, with no lymph- and angio- invasion, negative for AE 1-3, S100, ACTH, chromogranine, positive for synaptophysine and NSE).

Clinical remission hormonal profile

\begin{tabular}{|l|l|}
\hline morning cortisol & $401,8 \mathrm{pmol} / \mathrm{I}$ \\
\hline free testosterone & $0.7 \mathrm{nmol} / \mathrm{I}$ \\
\hline free androgen index & 1.4 \\
\hline DHEAS & $1.5 \mathrm{nmol} / \mathrm{I}$ \\
\hline SHBG & $50.3 \mathrm{nmol} / \mathrm{I}$ \\
\hline TSH & $2.31 \mathrm{mIU} / \mathrm{ml}$ \\
\hline ACTH & $16.8 \mathrm{pmol} / \mathrm{I}$ \\
\hline
\end{tabular}

In June 2012 PET/CT scan was performed, with complete negative results. Synacthen test after surgery showed sufficient cortisol reserve. Patient is now in our dispensarization, in conclusion with oncologist no adjuvant treatment was recommended.

\section{I S C U S S I O N}

In comparison with literature, testosterone-secreting oncocytic adrenocortical carcinoma was firstly described in 2010 in New Zealand and our case is probably the third case of this extremely unique malignancy in the world. 